\title{
Antimicrobial Susceptibility Pattern of Extended Spectrum Beta-lactamase (ESBL) and Non ESBL Producing Pseudomonas aeruginosa, Isolated from Pus Samples from a Tertiary Care Hospital in Bihar
}

\author{
Ankur Kumar, Suprakash Das, Nahid Anjum, Vikash Oraon and Sushmita Das*
}

Department of Microbiology, All-India Institute of Medical Sciences (AIIMS), Patna, India

*Corresponding author

\author{
A B S T R A C T
}

\section{Keywords \\ Pseudomonas aeruginosa, Extended spectrum beta-lactamase, Non extended spectrum beta-lactamase, Antibiogram}

Article Info

Accepted:

26 May 2020

Available Online:

10 June 2020
Pseudomonas aeruginosa is a gram negative bacillus that colonizes in moist environment of the hospital settings with occurrence of antimicrobial resistance. Increasing resistance to beta-lactam drugs, especially the 3rd-generation cephalosporins, in Pseudomonas aeruginosa is predominantly due to the production of extended spectrum beta-lactamases (ESBLs). This was a laboratory based observational study carried out over a period of 7 months from April 2019 to December 2019. A total of 207 pus samples from different patient sources of the hospital were collected and processed in the microbiology laboratory. Among these samples, positive clinical isolates of Pseudomonas aeruginosa were recovered. Next, ESBL production in all these isolates was detected by using double disc synergy test (DDST). P. aeruginosa were also tested against different antibiotics for determination of the antibiogram of these isolates. Out of 207 pus samples, $45(21.7 \%)$ clinical isolates of $P$. aeruginosa were detected. Out of these, $26.6 \%$ of the $P$. aeruginosa isolates $(n=12)$ were confirmed to be ESBL producers by the DDST method and rest $73.3 \%$ were non-ESBL producer $(n=33)$. Our results showed that the ESBL strains were multi-drug resistant but colistin sensitive. Our results show that one-fourth of $P$. Aeruginosa clinical isolates express ESBLs; and were resistant to commonly used antibiotics inclusive of some beta-lactams and non-beta-lactam antibiotics. There is therefore need for proper monitoring and detection of the ESBL strain for guiding suitable therapy and to contain their nefarious effect on antibiotics.

\section{Introduction}

Pseudomonas aeruginosa is an important opportunistic nosocomial pathogen that causes a variety of infections such as otitis, mastitis, hemorrhagic pneumonia, urinary tract Infections, wound and burn infections in humans ${ }^{(1,2)}$. Globally, the urgent problem inpublic health is the increasing resistance to commonly used antibiotics in potentially pathogenic Pseudomonas aeruginosa. ESBL production in $P$. aeruginosa has been reported previously; and show remarkable resistance to different classes of antibiotics, including penicillins and cephalosporins ${ }^{(3,4)}$. ESBLs are newer beta-lactamases that confer resistance to some of the latest beta-lactam antibiotics, especially the cephalosporins ${ }^{(2,5)}$. ESBLs are 
encoded by genes located on bacterial plasmids which also carry genes responsible for resistance to many other antimicrobials such as aminoglycosides, tetracyclines and sulphonamides $^{(6)}$. They are derived from the earlier beta-lactamases such as the TEM enzymes, SHV and OXA-beta-lactamases with a narrower-spectrum of activity in terms of the antibiotics they degrade; and ESBLs are largely responsible for the multidrug resistance amongst Gram negative bacteria $^{(1,7,8)}$.

All ESBL-type enzymes are categorized into two structural ambler classes, viz. A and D. In $P$. aeruginosa strains, the ESBL enzymes of both these classes are observed, primarily $\beta$ lactamases from the PER, $\operatorname{GES}^{(9)}, \operatorname{VEB}^{(10,11)}$, $\mathrm{BEL}^{(12,13)}$, and $\mathrm{PME}^{(14)}$ family (belonging to class A) and from the OXA family (class D), named the extended-spectrum class $\mathrm{D} \beta$ lactamases (ES-OXAs) ${ }^{(15)}$.

Additionally, in a few $P$. aeruginosa isolates, the presence of ESBLs similar to the Enterobacteriaceae family, such as TEM, $\mathrm{SHV}^{(16)}$ and CTX-M-type, was described.

Resistance to antimicrobial agents is an increasing clinical problem and is a recognized global public health threat. $P$. aeruginosa shows a particular propensity for the development of resistance. The emergence of resistance in $P$. aeruginosa also limits future therapeutic choices and is associated with increased rates of mortality and morbidity and higher costs ${ }^{(17,18)}$.

Failure to detect pathogenic ESBL-bacteria routinely in the clinical microbiology laboratory leads to treatment failure (especially with the cephalosporins and betalactams), prolonged illness, prolonged hospitalization, inappropriate antibiotic prescription etc. So it is important to identify ESBL-producing $P$. aeruginosa isolates and their antibiogram for lowering the rate of treatment failure in hospital settings. To the best of our knowledge, there is no study from Bihar state on ESBL-producing clinical isolates of P.aeruginosa. Therefore, our current study was taken up with the aim of identifying ESBL-producing clinical isolates of P.aeruginosa in pus samples acquired from OPD and IPD of a tertiary care hospital in Bihar and study their resistance pattern with different antibiotics.

\section{Materials and Methods}

This was a laboratory based observational study. Pseudomonas aeruginosa isolates were recovered from the pus sample collected at Microbiology department, AIIMS Patna during April 2019 to December 2019 (7 months). All study protocols were approved by the Institutional Review Boards and Ethical Committee.

\section{Pus samples}

Pus samples were collected from different departments (i.e. from Trauma \& Emergency, Surgery, Orthopaedics, Gastroenterology, Pulmonary Medicine, Paediatrics and Medicine department) of AIIMS Patna during the study period.

\section{Confirmation tests for $\boldsymbol{P}$. aeruginosa}

The collected pus samples were processed for identification and detection of $P$. aeruginosa by direct microscopy, gram's staining, inoculation in Blood Agar (BA), MacConkey Agar (MA) and Nutrient agar (NA) media and incubated at $37^{\circ} \mathrm{C}$ for $24-48$ hours under aerobic conditions. After growth of colonies, the samples were subjected to different biochemical tests for confirmation of $P$. aeruginosa, viz. catalase test, oxidase test, indole test, semisolid agar test, citrate test and TSI test. 


\section{Double disc synergy test (DDST)}

Firstly, we aimed to investigate and identify ESBL producing clinical strains of P.aeruginosa. ESBL production in all these isolates are detected by using double disc synergy test as described by Jarlier ${ }^{(19)}$. Synergy was determined between a disc of amoxyclav $30 \mu \mathrm{g}(20 \mu \mathrm{g}$ amoxicillin \& $10 \mu \mathrm{g}$ clavulanic acid) and Ceftazidime $(30 \mu \mathrm{g})$ disc, placed $15 \mathrm{~mm}$ apart on a lawn culture of the isolate, on Mueller Hinton agar (MHA). The plates were incubated at $37^{\circ} \mathrm{C}$ for $18-24 \mathrm{hrs}$. The test organism was considered to produce ESBL phenotypically ${ }^{(20)}$ as the zone size around the antibiotic disc increased towards the amoxyclav disc (Figure 1). Escherichia coli ATCC 25922 was used as a negative control for the ESBL and $P$. aeruginosa ATCC 27853 were used as a control strain for a positive $\mathrm{ESBL}^{(21)}$.

\section{Antimicrobial susceptibility testing (AST)}

P. aeruginosa are intrinsic resistant ${ }^{(22)}$ to Ampicillin, Amoxicillin, Ampicillinsubactam, Amoxicillin-clavunate, Cefotaxim, Ceftriaxone, Ertapenam, Tetracycline, Tigecycline, Trimethoprim, TrimethoprimSulfamethoxazole, Chloramphenicol. So, $P$. aeruginosa were tested against different susceptible antibiotics and commonly used discs was Amikacin (30 $\mu \mathrm{g})$, Aztreonam(30 $\mu \mathrm{g})$, Ceftazidime $(30 \mu \mathrm{g})$, Ceftazidimeclavulanate $(30 / 10 \mu \mathrm{g})$, Cefepime $(30 \mu \mathrm{g})$, Cefoperazone-sulbactam $\quad(100 / 10 \mu \mathrm{g})$, Ciprofloxacin $(5 \mu \mathrm{g})$, Colistin $(10 \mu \mathrm{g})$, Cotrimoxazole (Trimethoprimsuifamethoxazole 1.25/23.75 $\mu \mathrm{g})$, Gentamicin $(10 \mu \mathrm{g})$, Imipenem $(10 \mu \mathrm{g})$, Levofloxacin (5 $\mu \mathrm{g}), \quad$ Meropenam $(10 \quad \mu \mathrm{g}) \quad$ and Piperacillin/Tazobactam $(100 / 10 \mu \mathrm{g})$. Zone of inhibition was recorded as "Sensitive" or "Resistant" according to the Clinical and Laboratory Standards Institute (CLSI) guideline-2019 ${ }^{(22)}$ (Figure 2 and 3).
Furthermore, we have performed colistin MIC test by E-strip (Ezy $\left.{ }^{\mathrm{TM}} \mathrm{CL}, \mathrm{HIMEDIA}\right)$ and macro-dilution method. For macro-dilution method, we made colistin drug of $1 \mathrm{mg} / \mathrm{ml}$ concentration (by mixing $80 \mathrm{ml}$ distilled water in a $80 \mathrm{mg}$ dry powder colistin vial) and then made a serial dilution of drug of $8 \mathrm{mcg} / \mathrm{ml}$, $4 \mathrm{mcg} / \mathrm{ml}$, $\quad 2 \mathrm{mcg} / \mathrm{ml}$, $\quad 1 \mathrm{mcg} / \mathrm{ml}$ and $0.5 \mathrm{mcg} / \mathrm{ml}$ (by adding $2 \mathrm{ml}$ of $0.5 \mathrm{McF}$ arland $P$. aeruginosa suspension to already taken 16 mcl colistin drug, thus achieving the final concentration of $8 \mathrm{mcg} / \mathrm{ml}$. Then, we again made serial double dilutions to reach up to $0.5 \mathrm{mcg} / \mathrm{ml}$ concentration (Figure 4 ). MIC was the minimum drug concentration where no bacterial growth was found and designated as resistant if MIC is $>$ or $=4 \mathrm{mcg} / \mathrm{ml}^{(22)}$.

\section{Results and Discussion}

The total no. of 207 pus samples were collected from different departments of AIIMS, Patna. The distribution of samples per department was as follows: viz. from Trauma \& Emergency 35.3\%, Surgery $29.5 \%$, Orthopaedics $15.9 \%$, Gastroenterology $9.2 \%$, Pulmonary Medicine 4.3\%, Paediatrics 3.4\% and from Medicine $2.4 \%$. We have processed all the 207 pus samples and the 45 (i.e. $21.7 \%$ ) confirmed $P$. aeruginosa clinical isolates were further processed for antibiogram information. $P$. aeruginosa isolates that were obtained as a pure and predominant growth from the clinical specimens were only considered for the present study. $P$. aeruginosa was confirmed by examining the gram's staining morphology (presence of gram negative, non sporing bacilli), colony characteristics on MA (nonlactose fermenting colonies), BA (mostly hemolytic colonies), NA (colonies with diffusible pigment of bluish-green or greenish-yellow in colour, and emission of a characteristic fruity odour) and with the results of biochemical tests which were catalase test - positive, oxidase test - positive, 
absence of indole ring, positive motility on semisolid agar, utilization of citrate and TSI$\mathrm{k} / \mathrm{k}$ reaction without $\mathrm{H}_{2} \mathrm{~S}$ production.

Out of $45 P$. aeruginosa isolates, 12 (i.e.26.6\%) were found to be positive for ESBL production according to the DDST method and rest 33 were non-ESBL producer (i.e. 73.3\%) (Figure 5). Non ESBL $P$. aeruginosa were mostly sensitive to commonly used drugs (Ciprofloxacin, Gentamicin, Amikacin, Aztreonam, Cefepime, Ceftazidime, Imipenem, Meropenam, Piperacillin/Tazobactam, Cefoperazone- sulbactam) but most were resistant to Cotrimoxazole but still non of them resistant to colistin (Figure $6 \&$ summarized in Table 1,2). The most of ESBL $P$. aeruginosa were multi-drug resistant (drug resistance to more than or equal to three different classes of drug) and maximum sensitivity (100\%) was seen with Colistin followed by Piperacillin/ Tazobactam $(66.66 \%)$, Ceftazidime/ clavulanate $(66.66 \%)$, Imipenem (41.66\%) and Cefoperazonesulbactam (41.66\%). Monotherapy by Ceftazidime shows $68.66 \%$ sensitivity but when used in combination with clavulanateCeftazidime/ clavulanate $(30 / 10 \mu \mathrm{g})$ the overall sensitivity increased to $82.22 \%$ (Figure 6 \& Table 1, 2).

Table.1 Sensitivity and Resistant pattern of $P$. aeruginosa isolates (both ESBL \& NON-ESBL ) with different antibiotics

\begin{tabular}{|l|c|c|}
\hline Antibiotics & $\begin{array}{c}\text { Number of Sensitive Pseudomonas } \\
\text { Strains(Percentage) } \\
(\mathbf{n = 4 5})\end{array}$ & $\begin{array}{c}\text { Number of Resistant Pseudomonas } \\
\text { Strains (Percentage) } \\
(\mathbf{n}=\mathbf{4 5})\end{array}$ \\
\hline Ciprofloxacin & $29(64.44 \%)$ & $16(35.55 \%)$ \\
\hline Cotrimoxazole & $16(35.55 \%)$ & $29(64.44 \%)$ \\
\hline Gentamycin & $21(46.66 \%)$ & $14(31.11 \%)$ \\
\hline Amikacin & $33(73.33 \%)$ & $12(26.66 \%)$ \\
\hline Aztreonam & $33(73.33 \%)$ & $9(20 \%)$ \\
\hline Cefepime & $30(66.66 \%)$ & $15(33.33 \%)$ \\
\hline Ceftazidime & $31(68.66 \%)$ & $14(31.11 \%)$ \\
\hline Imipenem & $30(66.66 \%)$ & $14(31.11 \%)$ \\
\hline Meropenam & $29(64.44 \%)$ & $16(35.55 \%)$ \\
\hline $\begin{array}{l}\text { Piperacillin- } \\
\text { Tazobactam }\end{array}$ & $37(82.22 \%)$ & $5(11.11 \%)$ \\
\hline $\begin{array}{l}\text { Ceftazidime- } \\
\text { clavulanate }\end{array}$ & $37(82.22 \%)$ & $83(17.77 \%)$ \\
\hline $\begin{array}{l}\text { Cefoperazone- } \\
\text { sulbactam }\end{array}$ & $35(71.11 \%)$ & $9(20 \%)$ \\
\hline Colistin & $45(100 \%)$ & $0(0 \%)$ \\
\hline
\end{tabular}


Table.2 Sensitivity and Resistant pattern of ESBL \& NON-ESBL P. aeruginosa isolates with different antibiotics

\begin{tabular}{|c|c|c|c|c|c|c|c|}
\hline \multirow{3}{*}{ Antibiotics } & \multicolumn{6}{|c|}{ Number of strains(Percentage) } & \multirow{3}{*}{ P Value } \\
\hline & \multicolumn{3}{|c|}{$\begin{array}{l}\text { ESBL Pseudomonas } \\
(\mathrm{n}=12)\end{array}$} & \multicolumn{3}{|c|}{$\begin{array}{c}\text { NON-ESBL Pseudomonas } \\
(\mathrm{n}=\mathbf{3 3})\end{array}$} & \\
\hline & $\mathbf{S}$ & $\mathbf{I}$ & $\mathbf{R}$ & $\mathbf{S}$ & $\mathbf{I}$ & $\mathbf{R}$ & \\
\hline Ciprofloxacin & $5(41.66 \%)$ & - & $7(58.33 \%)$ & $24(72.72 \%)$ & - & $9(27.27 \%)$ & 0.054244 \\
\hline Cotrimoxazole & $3(25 \%)$ & - & $9(75 \%)$ & $13(39.39 \%)$ & - & $\begin{array}{c}20 \\
(60.60 \%)\end{array}$ & 0.372382 \\
\hline Gentamycin & $4(33.33 \%)$ & - & $8(66.66 \%)$ & $27(81.81 \%)$ & - & $6(18.18 \%)$ & 0.001891 \\
\hline Amikacin & $5(41.66 \%)$ & - & $758.33 \%)$ & $28(84.84 \%)$ & - & $5(15.15 \%)$ & 0.003771 \\
\hline Aztreonam & $7(58.33 \%)$ & - & $5(41.66 \%)$ & $26(78.78 \%)$ & 3 & $4(12.12 \%)$ & 0.170022 \\
\hline Cefepime & $4(33.33 \%)$ & - & $8(66.66 \%)$ & $26(78.78 \%)$ & - & $7(21.21 \%)$ & 0.004231 \\
\hline Ceftazidime & $5(41.66 \%)$ & - & $7(58.33 \%)$ & $26(78.78 \%)$ & - & $7(21.21 \%)$ & 0.017376 \\
\hline Imipenem & $4(33.33 \%)$ & 1 & $7(58.33 \%)$ & $26(78.78 \%)$ & - & $7(21.21 \%)$ & 0.004231 \\
\hline Meropenam & $5(41.66 \%)$ & - & $7(58.33 \%)$ & $24(72.72 \%)$ & - & $9(27.27 \%)$ & 0.054244 \\
\hline $\begin{array}{l}\text { Piperacillin- } \\
\text { Tazobactam }\end{array}$ & $7(58.33 \%)$ & 1 & $4(33.33 \%)$ & $30(90.90 \%)$ & 2 & $1(3.03 \%)$ & 0.011486 \\
\hline $\begin{array}{l}\text { Ceftazidime- } \\
\text { clavulanate }\end{array}$ & $8(66.66 \%)$ & - & $4(33.33 \%)$ & $29(87.88 \%)$ & - & $4(12.12 \%)$ & 0.099793 \\
\hline $\begin{array}{l}\text { Cefoperazone- } \\
\text { sulbactam }\end{array}$ & $5(41.66 \%)$ & - & $7(58.33 \%)$ & $30(90.90 \%)$ & 1 & $2(6.06 \%)$ & 0.000442 \\
\hline Colistin & $12(100 \%)$ & - & $0(0 \%)$ & $33(100 \%)$ & - & $0(0 \%)$ & $\ldots .$. \\
\hline
\end{tabular}

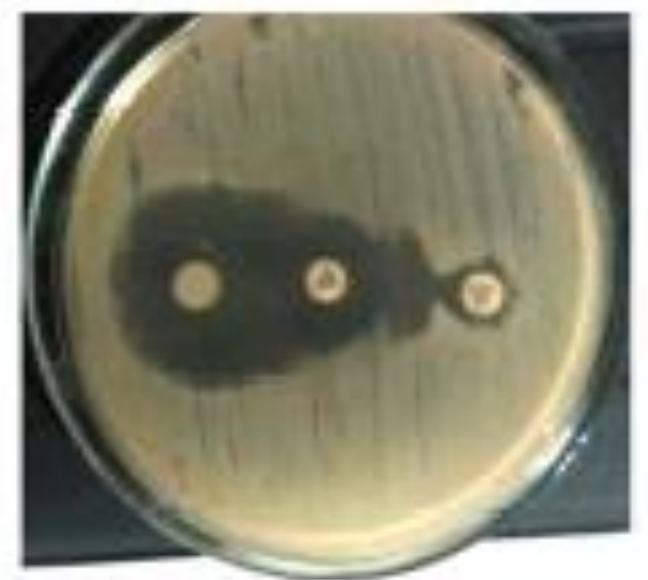

Fig 1: Double disc synergy test (DDST)

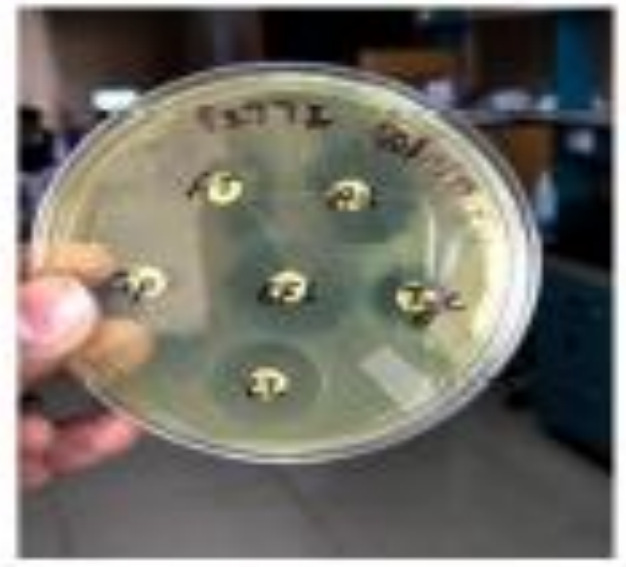

Fin 2: AST 


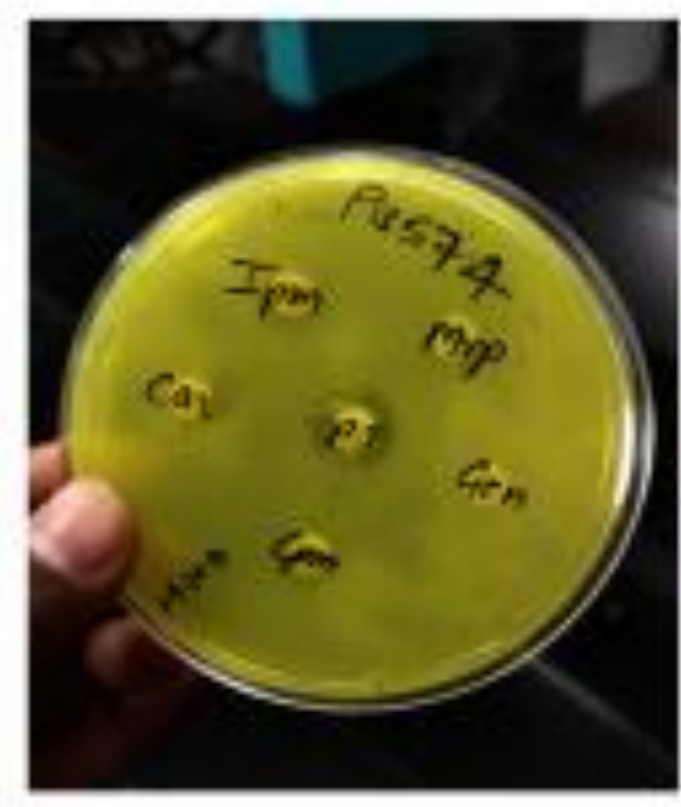

Fig 3: AST 2

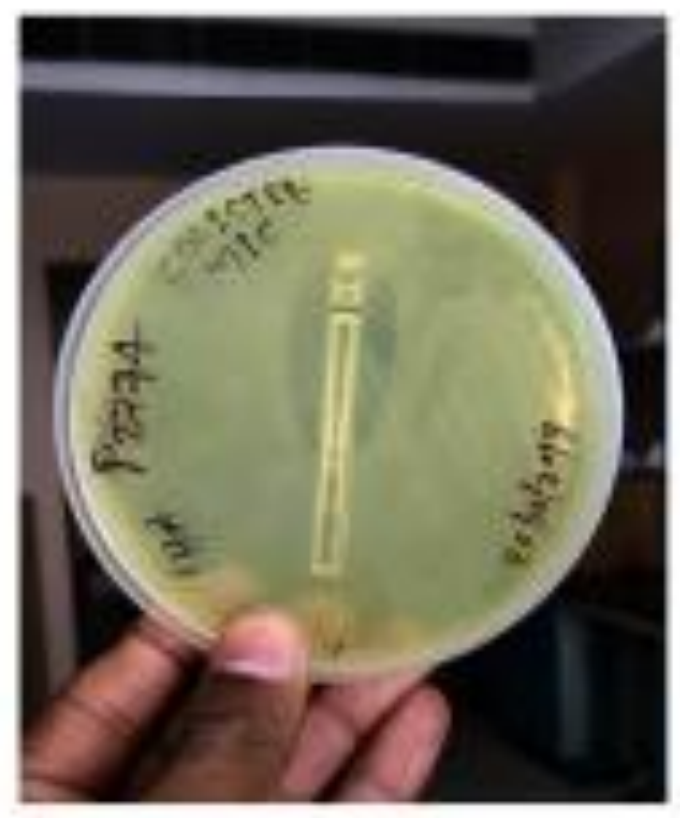

Fig 4: MiC Colistin by E-strip

Figure.5 Distribution of $P$. aeruginosa isolates according to ESBL production

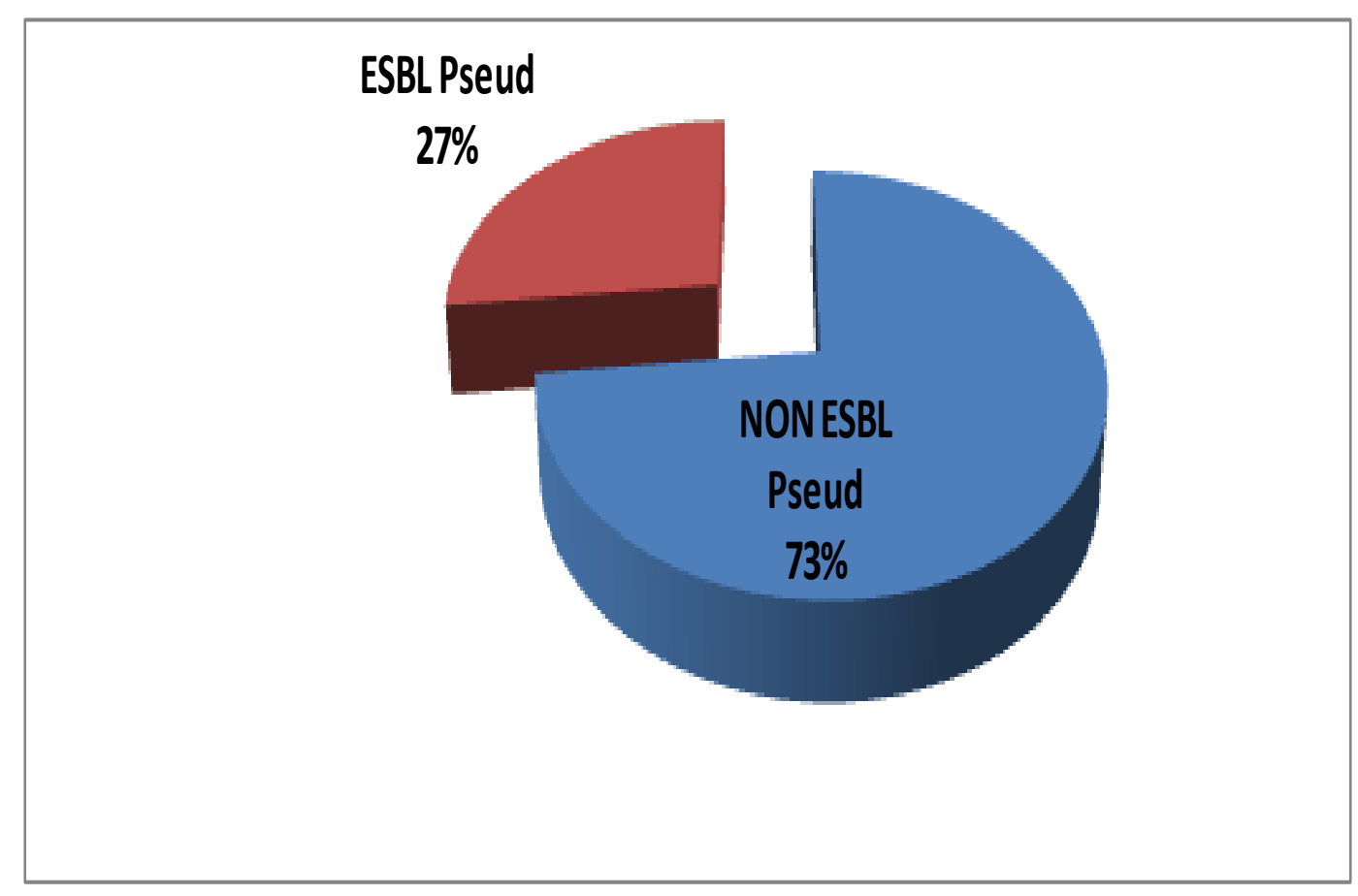


Figure.6 Comparison of Sensitivity pattern between ESBL \& NON-ESBL $P$. aeruginosa isolates with different antibiotics

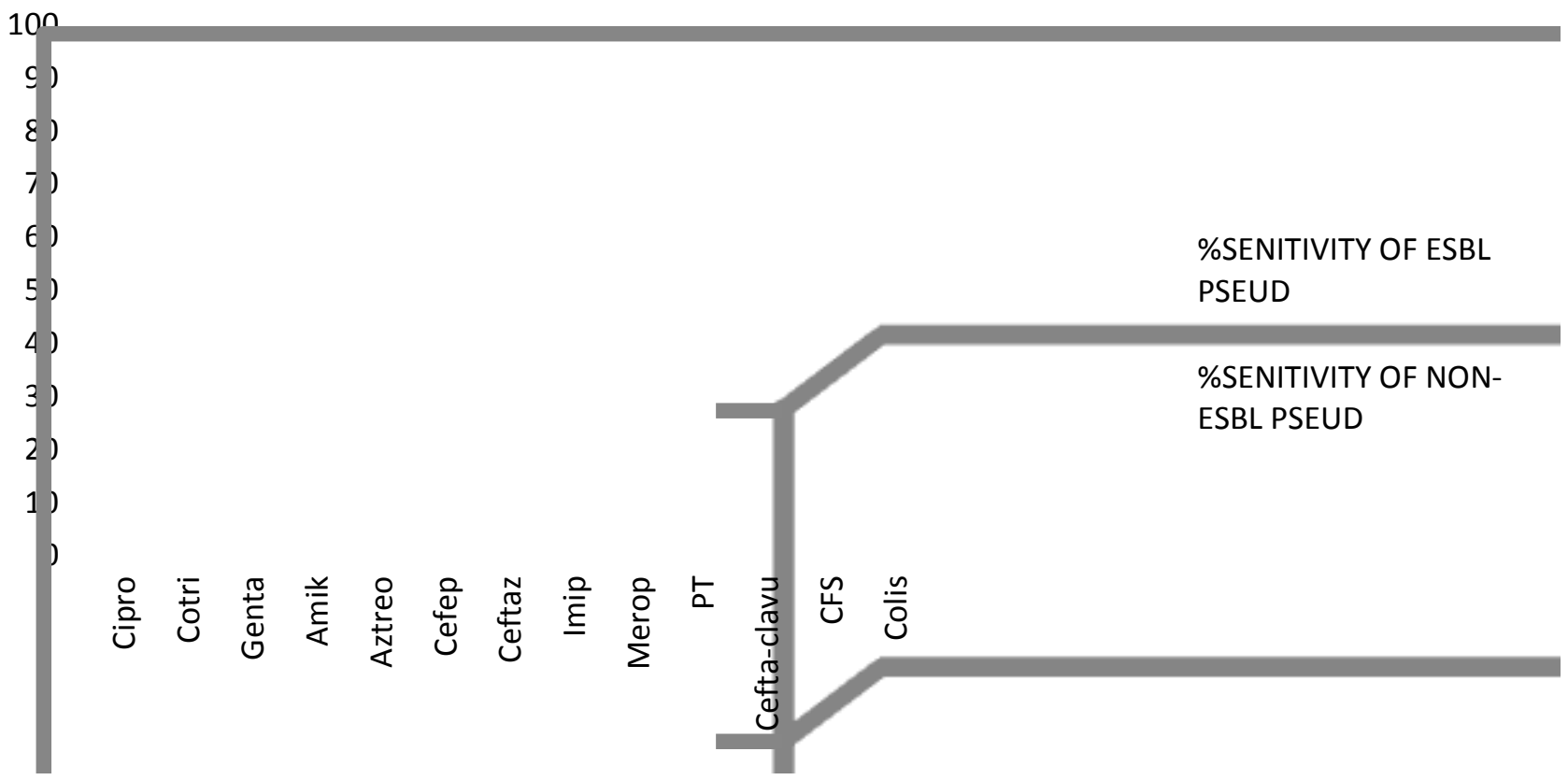

The study results show $27 \%$ (12 out of 45 ) were ESBL producing strains among all $P$. aeruginosa isolates. The studies conducted by others depicted very lower rates of ESBL production in $P$. aeruginosa $3.7 \%, 4.2 \%$ and $7.7 \%$, respectively by $\mathrm{Lim} \mathrm{KT}$ et al., in $2009^{(23)}$, Woodford et al., in $2008^{(24)}$ and Jacobson KL et.al in $1995^{(25)}$. A study conducted by Agrawal et al., (26) in Haryana, India in 2018 found $20.27 \%$ ESBL producing strains. In addition, the results of others, showed more higher rates $(20.3 \%$ to $46 \%)$ of ESBLs in $P$. aeruginosa isolated in their investigations of Mirsalehian et $a l^{(27)}$, Ullah F et.al $l^{(28)}$ and Shah Cheraghi et $a l^{(29)}$. In general, there is a considerable geographic difference in the prevalence of ESBLs in different countries.

This study reported the highest resistance rate to Cotrimoxazole, Gentamycin, Ciprofloxacin. However, resistance value of gentamicin was much lower than the values reported in other studies, viz. Fadeyi et al., ${ }^{(30)}$ and Ogundipeju et al., (31). In the current study, Ciprofloxacin exhibited high susceptibility pattern (64.44\%), while Gul et $a l .{ }^{(32)}$ reported that more than $90 \%$ of isolates were sensitive to ciprofloxacin. This might be a characteristic of the clinical strains of $P$. aeruginosa prevailing in Bihar state. Resistance to piperacillin-tazobactam as reported by Javiya et al., ${ }^{(33)} 73.21 \%$ is much higher than that reported in our study i.e. 9 $(11.1 \%)$.

Reports present the resistance to carbapenemsto be around 35\%, results from reduced levels of drug accumulation or increased expression of pump efflux or production of $\operatorname{ESBL}^{(34,35,36)}$. Interestingly, carbapenems are still considered to be the treatment of choice against ESBL associated infections. Cephalosporins, especially the third-generation ceftadizime, are known as anti-pseudomonal drugs has demonstrated high susceptibility pattern about $68.66 \%$. In contrast, cephalosporins tested in a study 
conducted in Ibadan, southwestern Nigeria ${ }^{(37)}$, showed that $90 \%$ of the isolates were sensitive $^{(38)}$ but study conducted in Malaysia $^{(23)}$ show $40 \%$ sensitivity. In present study $100 \%$ of isolates were found to be susceptible to colistin among all ESBL and Non ESBL strains. This colistin sensitivity found in our current study is comparable to results of Das et al ${ }^{(39)}$. That also showed $100 \%$ sensitivity.

In conclusion, Pseudomonas aeruginosa is one of the most important nosocomial pathogens in health care system. The presence of ESBL in $P$. aeruginosa tend to increase, resulting in ineffectiveness of many antimicrobial agents. The emergence of resistance in $P$. aeruginosa strains that had been consistently susceptible to standard antimicrobial therapy is of growing clinical concern, as is the alarming trend to multidrug resistance. With this in mind, the early detection of ESBLs, the judicious use of appropriate antibiotics and the implementation of infection control strategies are major concerns to avoid the spread of this threat in the hospital. In this study, $P$. aeruginosa showed resistance to various antimicrobial agents but was susceptible to colistin. This finding may help in deciding upon the definitive antimicrobial therapy as single drug or in combination therapy. Further studies are needed on better use of the existing antibiotics along with infection controls measures, antimicrobial stewardship programs and should fully focus on search for new antibiotics.

\section{References}

1. Ejikeugwu $\mathrm{C}$, Iroha I, Adikwu $\mathrm{M}$ and Esimone C. Susceptibility and Detection of Extended Spectrum $\beta$-Lactamase Enzymes from Otitis Media Pathogens. American Journal of Infectious Diseases. 2013; 9(1): 24-29.

2. Paterson DL, Bonomo RA. Extended- spectrum $\beta$-lactamases: a clinical update. ClinMicrobiol Rev. 2005; 18: 657 \pm 686 . https://doi.org/10.1128/CMR.18.4.657-

686.2005 PMID: 16223952

3. Weldhagen GF, Poirel L and Nordmann P. Ambler Class A extended spectrum $\beta$ lactamases in Pseudomonas aeruginosa: novel developments and clinical impact. Antimicrobial Agents Chemother. 2003; 47: 2385-2392.

4. Weldhagen GF, Poirel L and Nordmann P. Ambler Class A extended spectrum $\beta$ lactamases in Pseudomonas aeruginosa: novel developments and clinical impact. Antimicrobial Agents Chemother. 2003; 47: 2385-2392.

5. Jacoby GA and Munoz-Price LS. Mechanisms of Disease: The New $\beta$ Lactamases. N Engl J Med. 2005; 352: 38091.

6. Pitout JDD, Nordmann P, Laupland KB and Piorel L. Emergence of Enterobacteriaceae producing extended - spectrum $\beta$ lactamases (ESBLs) in the community. Journal of Antimicrobial Chemotherapy. 2005; 1-8.

7. Ejikeugwu $\mathrm{C}$, Iroha I, Adikwu $\mathrm{M}$ and Esimone C. Susceptibility and Detection of Extended Spectrum $\beta$-Lactamase Enzymes from Otitis Media Pathogens. American Journal of Infectious Diseases. 2013; 9(1): 24-29.

8. Bradford PA. Extended - Spectrum $\beta-$ Lactamases in the 21st century: Characterization, Epidemiology, and Detection of this Important Resistance Threat. Clinical Microbiology Reviews. 2001; 14(4): 933-951.

9. Garza-Ramos U, Barrios H, Reyna-Flores F, Tamayo-Legorreta E, Catalan-Najera JC, Morfin-Otero R, et al., Widespred of ESBLand carbapenemase GES-type genes on carbapenem-resistant Pseudomonas aeruginosa clinical isolates: a multicenter study in Mexican hospitals. Diagn Microbiol Infect Dis.2015; 8: 135 \pm 137.

10. Potron A, Poirel L, Nordmann P. Emerging broad-spectrum resistance in Pseudomonas aeruginosa and Acinetobacter baumannii: 
mechanisms and epidemiology. Int $\mathbf{J}$ Antimicrob Agents. 2015; 45: 568 \pm 585 . https://doi.org/10.1016/j.ijantimicag.2015.0 3.001 PMID: 25857949

11. Vatcheva-Dobrevska R, Mulet X, Ivanov I, Zamorano L, Dobreva E, Velinov T, et al., Molecular epidemiology and multidrug resistance mechanisms of Pseudomonas aeruginosa isolates from Bulgarian hospitals. Microb Drug Resist. 2013; 19:355 \pm 361 .

https://doi.org/10.1089/mdr.2013.0004

PMID: 23600605

12. Poirel L, Brinas L, Verlinde A, Ide L, Nordmann P. BEL-1, a novel clavulanic acid-inhibited extended spectrum $\beta$ lactamase, and the class 1 integron In120 in Pseudomonas aeruginosa. Antimicrob Agents Chemother. 2005; 49: 3743 \pm 3748 . https://doi.org/10.1128/AAC.49.9.37433748.2005 PMID: 16127048

13. Glupczynski Y, Bogaerts P, Deplano A, Berhin C, Huang TD, Van Eldere J, et al., Detection and characterization of class A extended-spectrum- $\beta$-lactamase-producing Pseudomonas aeruginosa isolates in Belgian hospitals. J Antimicrob Chemother. 2010; 65: 866 $\pm 871 . P M I D: 20200037$

14. Tian GB, Adams-Haduch JM, Bogdanovich T, Wang HN, Doi Y. PME-1, an extendedspectrum $\beta$-lactamase identified in Pseudomonas. Antimicrob Agents Chemother. 2011; 55: 2710 \pm 2713 . https://doi.org/10.1128/AAC.01660-10 PMID: 21402845

15. Poirel L, Naas T, Nordmann P. Diversity, epidemiology, and genetics of class $\mathrm{D} \beta$ lactamases. Antimicrob Agents Chemother. 2010; 54 : 24 238 . https://doi.org/10.1128/AAC.01512-08 PMID: 19721065

16. Bae IK, Suh B, Jeong SH, Wang KK, Kim YR, Yong D, et al., Molecular epidemiology of Pseudomonas aeruginosa clinical isolates from Korea producing $\beta$-lactamases with extended-spectrum activity. Diagn Microbiol Infect Dis. 2014; 79: 373 \pm 377 . https://doi.org/10.1016/j.diagmicrobio.2014. 03.007 PMID:24792837
17. Syrmis MW, O'Carrol MR, Sloots TP, Coulter C, Wainwritgh CE, Bell SC, et al., Rapid genotyping of Pseudomonas aeruginosa isolates harboured by adult pediatric patients with cystic fibrosis using repetitive element-based PCR assays. J Med Microbial. 2004; 53: 1089-96.

18. Yu WL, Chuang YC, Rasmussen JW. Extended spectrumbeta-lactamases in Taiwan: epidemiology, detection, treatment and infection control. J Microbiol Immunol Infect. 2006; 39: 264-77.

19. Weldhagen GF, Poirel L and Nordmann P. Ambler Class A extended spectrum $\beta$ lactamases in Pseudomonas aeruginosa: novel developments and clinical impact. Antimicrobial Agents Chemother. 2003; 47: 2385-2392.

20. Extended-spectrum beta-lactamaseproducing Pseudomonas aeruginosa in camel in Egypt: potential human hazard, US National Library of Medicine National Institutes of Health

21. Mahmoud Elhariri, Dalia Hamza, Rehab Elhelw, and Sohad M. Dorgham. Extendedspectrum beta-lactamase-producing Pseudomonas aeruginosa in camel in Egypt: potential human hazard. https://www.ncbi.nlm.nih.gov/pmc/articles/ PMC5374582/

22. Clinical and Laboratory Standards Institute. Performance standards for antimicrobial susceptibility testing. 26th ed. CLSI supplement M100S. Wayne, Pennsylvania USA, 2019.

23. Lim KT, Yasin RM, Yeo CC, Puthuncheary SD, BalanG, Maning $\mathrm{N}$, et al., Genetic fingerprinting and antimicrobial susceptibility profiles of Pseudomonas aeruginosa hospital isolates in Malaysia. J Microbial Immunol Infect. 2009;42:197209.

24. Woodford N, Zhang J, Kaufmann ME, Yarde S, Tomas M, Faris C, et al., Detection of Pseudomonas aeruginosa isolates producing VEB-type extended spectrum $\beta$ lactamases in the United Kingdom. J Antimicrob Chemother. 2008; 62(6):126568. 
25. Jacobson KL, Cohen SH, Inciardi JF, King $\mathrm{JH}$, Lippert WE, Iglesias $\mathrm{T}$, et al., The relationship between antecedent antibiotic use and resistance to extended spectrum cephalosporins in group I $\beta$-lactamase producing organisms. Clin Infect Dis. 1995; 21:1107-13.

26. Aggarwal R, Chaudhary U, Bala K. Detection of extended-spectrum $\beta$ lactamase in Pseudomonas aeruginosa. Indian J Pathol Microbiol. 2008; 51:222-24.

27. Mirsalehian A, Feizabadi M, Nakhjavani FA, Jabalameli F, Goli H, Kalantari N. Detection of VEB-1, OXA-10 and PER-1 genotypes in extended-spectrumbetalactamase-producing Pseudomonas aeruginosa strains isolated from burn patients. Burns. 2010; 36(1):70-4.

28. Ullah F, Malik SA, Ahmed J. Antimicrobial susceptibility and ESBL prevalence in Pseudomonas aeruginosa isolated from burn patients in the NorthWest of Pakistan. Journal of the International Society forBurn Injuries 2009;35(7):1020-25.

29. Shah Cheraghi F, Nikbin VS, Shouraj F. PCR detection of PER \& VEB \& SHV and TEM betalactamases in multidrug resistant $P$. aeruginosa isolatedfrom wound infections in two hospitals of Tehran. Iranian Journal of Medical Microbiology 2008;1(4):21-

30. Fadeyi A, Akanbi AA, Ndubisi C, OnileBA. Antibiotic disc sensitivity pattern of Pseudomonas aeruginosa isolates obtained from clinical specimens in Ilorin, Nigeria. Nigerian Journal of Medical Sciences 2005; 34(3): 303-6.

31. Ogundipeju OO, Nwobu RAU. Occurrence of Pseudomonas aeruginosa in post- operative wound infection. Pakistan Journal of Medicine. 2004; 20:187-91.

32. Gul AA, Ali L, Rahim E, Ahmed S. Chronic suppurative otitis media; frequency of Pseudomonas aeruginosa in patients and its sensitivity to various antibiotics. Professional Med J. 2007; 14:411-5.

33. Javiya VA, Ghatak SB, Patel KR, Patel JA. Antibiotic susceptibility patterns of Pseudomonas aeruginosa at a tertiary care hospital in Gujarat, India. Indian J Pharmacol. 2008; 40(5):230-34.

34. Gupta E, Mohanty S, Sood S, Dhawan B, Das BK, Kapil A. Emerging resistance to Carbapenems in a tertiary care hospital in North India. Indian J Med Res. 2006; 124:95-8.

35. Kurokawa H, Yagi T, Shibata N, Shibayama $\mathrm{K}$, Arakawa Y. Worldwide proliferation of Carbapenem resistant gram negative bacteria. Lancet. 1999; 354: 955.

36. Navneeth BV, Sridaran D, Sahay D, Belwadi MR.A preliminary study on metallo $\beta$ - lactamase producing Pseudomonas aeruginosa in hospitalized patients. IndianJ Med Res. 2002;116:264-7.

37. Oni AA, Nwaorgu OGB, Bakare RA, Ogunkunle MO, Toki RA. The discharging ears in adults in Ibadan, Nigeria; causative agents and antimicrobial sensitivity pattern. Afr J Clin Exp Microbiol 2002; 3:3-5.

38. Das S., Azad M., Bima K., Oraon V. Antimicrobial Susceptibility Pattern of Pseudomonas aeruginosa with Special Reference to ESBL Producers from Various Clinical Samples at a Tertiary Care Center in Bihar. International Journal of Research and Review. Vol.7; Issue: 1; January 2020.

\section{How to cite this article:}

Ankur Kumar, Suprakash Das, NahidAnjum, Vikash Oraon and Sushmita Das. 2020. Antimicrobial Susceptibility Pattern of Extended Spectrum Beta-lactamase (ESBL) and Non ESBL Producing Pseudomonas aeruginosa, Isolated from Pus Samples from a Tertiary Care Hospital in Bihar. Int.J.Curr.Microbiol.App.Sci. 9(06): 3646-3655.

doi: https://doi.org/10.20546/ijcmas.2020.906.429 